\title{
Outcomes of asthma education: Results of a multisite evaluation
}

\author{
Wilma M Hopman MA ${ }^{1,2}$, Nancy Garvey RRT/RRCP CAE ${ }^{3 *}$, Jennifer Olajos-Clow RN MSC CAE ${ }^{4}$, \\ Andrea White-Markham RRT/RRCP CAE ${ }^{5}$, M Diane Lougheed MD MSc FRCPC ${ }^{1,6}$
}

WM Hopman, N Garvey, J Olajos-Clow, A White-Markham, MD Lougheed. Outcomes of asthma education: Results of a multisite evaluation. Can Respir J 2004;11(4):291-297.

BACKGROUND: This observational study compared the effectiveness of a standardized adult asthma education program administered in a variety of sites and practice settings on health care utilization, absenteeism, amount of leisure time missed and quality of life (using the Medical Outcomes Study 36-Item Short Form 1.0 [SF-36]).

METHODS: Seven asthma centres participated in an uncontrolled, multicentre, prospective, observational study using a pre-post design. Variables included hospital- and community-based centres, an academic hospital setting and the presence or absence of physician attendance. Trained asthma educators administered a guided selfmanagement education program, and standardized questionnaires were used for patient assessment at baseline and six months after education. RESULTS: Of the 517 patients enrolled at baseline, 396 were eligible for the six-month follow-up. Follow-up data were available for 252 patients. SF-36 data were collected for 241 patients at six sites, with follow-up data available for 103 of 155 eligible patients. Asthma education was associated with substantial improvements in scheduled and unscheduled physician visits, unscheduled specialist visits, emergency department visits, hospital admissions, hospitalized days, missed work or school days and missed days of leisure time. There were also statistically significant improvements in all but one SF-36 domain. These improvements were comparable across all geographical sites and physical settings. CONCLUSIONS: Standardized asthma education appears to be effective when administered in a variety of practice settings, and may be associated with significant improvements in patient outcomes. The significant decline in health care utilization implies that substantial health care savings may occur as a result of the implementation of standardized asthma education programs.

Key Words: Asthma; Education; Quality of life; SF-36; Utilization

A sta thma represents a serious burden of illness globally, and has a significant impact on health care utilization, activity and quality of life (1-4). According to the 1996 to 1997 National Population Health Survey, over 2.2 million Canadians have been diagnosed with asthma by a physician at some point in their lives, including $12.2 \%$ of those aged 19 years and younger and $6.3 \%$ of adults $(5)$.

\section{Les issues de l'éducation sur l'asthme : Les résultats d'une évaluation multisite}

HISTORIQUE : La présente étude par observation a permis de compare l'efficacité d'un programme normalisé d'éducation sur l'asthme destiné aux adultes administré dans divers établissements et milieux de pratique sur l'utilisation des soins de santé, l'absentéisme, le temps de loisir raté et la qualité de vie (au moyen du formulaire court en 36 questions de l'étude sur les issues médicales 1.0 [SF-36]).

MÉTHODOLOGIE : Sept centres de l'asthme ont participé à une étude avant-après par observation prospective, multicentrique et non contrôlée. Les variables incluaient des centres hospitaliers et communautaires, un milieu hospitalier universitaire et la présence ou l'absence de médecins. Des éducateurs formés sur l'asthme ont donné un programme de formation autogéré, et des questionnaires normalisés ont été utilisés pour évaluer les patients au début du programme et six mois après la formation. RÉSULTATS : Des 517 patients enrôlés, 396 étaient admissibles au suivi de six mois. Des données de suivi étaient disponibles pour 252 patients. Les données du SF-36 ont été colligées à l'égard de 241 patients de six établissements, et des données de suivi étaient disponibles à l'égard de 103 des 155 patients admissibles. L'éducation sur l'asthme s'associait à des améliorations marquées dans les rendez-vous prévus et imprévus avec le médecin, les rendez-vous imprévus avec le spécialiste, les visites à l'urgence, les hospitalisations, la durée d'hospitalisation, les absences du travail ou de l'école et les journées de loisirs ratées. On remarquait également des améliorations significatives dans tous les domaines du SF. 36, sauf un. Ces améliorations étaient comparables dans tous les emplacements géographiques et physiques.

CONCLUSIONS : L'éducation normalisée sur l'asthme semble être efficace lorsqu'elle est administrée dans divers milieux de pratique et peut s'associer à des améliorations marquées de l'issue des patients. La diminution importante du recours aux soins de santé indique que de grandes économies en santé peuvent découler de l'adoption de programmes d'éducation normalisés sur l'asthme.

Consensus reports routinely emphasize the importance of both pharmacological strategies and patient education to achieve acceptable control over asthma symptoms $(2,3,6)$. However, the effectiveness of consensus reports in influencing medical practice has been limited, in part due to the difficulties encountered in implementing guidelines $(7,8)$. Moreover, there is increasing evidence that a perceived lack of widely available,

*At the time of the study, Nancy Garvey was at the William Osler Health Centre, Brampton Hospital Campus, Brampton, Ontario

${ }^{1}$ Clinical Research Centre, Kingston General Hospital, Kingston, Ontario; ${ }^{2}$ The Department of Community Health and Epidemiology, Queen's

University, Kingston, Ontario; ${ }^{3}$ The Hospital for Sick Children, Toronto, Ontario; ${ }^{4}$ Asthma Education Centre, Kingston General Hospital, and School of Nursing, Queen's University, Kingston Ontario; ${ }^{5}$ William Osler Health Centre, Brampton Hospital Campus, Brampton, Ontario; 'Department of Medicine, Queen's University, Kingston, Ontario

Correspondence and reprints: Wilma Hopman, Clinical Research Centre, Angada 4, Room 5-426, Kingston General Hospital, Kingston, Ontario K7L 2V7. Telephone 613-549-6666 ext 4941, fax 613-548-2428, e-mail hopmanw@kgh.kari.net 
standardized asthma education programs is an important barrier to guideline implementation (7). There is also a paucity of literature comparing and documenting the effectiveness of asthma self-management programs (proven efficacious in clinical trial settings [9]) when implemented outside of a controlled study environment and across different settings.

The hypothesis of the present study was that a standardized asthma education program would result in improved outcomes, regardless of geographical site or physical setting. The primary objective was to compare the effectiveness of the education program on health care utilization (regular and unscheduled visits to general physicians and specialists, number of emergency room visits and hospitalizations, and length of stay), absenteeism, amount of leisure time missed and health-related quality of life (HRQOL) in a variety of settings. A secondary objective was to identify baseline characteristics associated with greater or lesser improvement in outcomes.

\section{PATIENTS AND METHODS}

\section{Patients}

Adults aged 16 years and older with asthma (American Thoracic Society definition [10]) who were attending a participating asthma centre or clinic between July 1996 and March 1998 were recruited. Patients were excluded if they had bronchiectasis, chronic bronchitis, chronic obstructive pulmonary disease, cystic fibrosis or emphysema. All patients were referred for education by family physicians, specialists and emergency departments on the basis of poor asthma control and/or an exacerbation of asthma. There were no self-referrals within the sample.

All participants provided written, informed consent. The study was approved by the Queen's University Health Sciences and Affiliated Teaching Hospitals Research Ethics Board (Kingston, Ontario) and the participating sites' local research ethics committees.

\section{Study design}

This was a multicentre, prospective, observational, comparative study conducted at seven sites across Canada. Five sites (one each from Nova Scotia, Newfoundland and British Columbia, and two from Ontario) were Community Asthma Care Centres (CACCs) (11-13). A sixth site was an Ontario community hospital and a seventh was an Ontario academic health sciences centre. The education program was used to complement usual care provided by the referring general practitioner, family physician or specialist at all centres. Patients referred to the academic health sciences centre site received an asthma specialist assessment in addition to the standardized education program.

Patients attended an initial visit and six-month follow-up visit to the education program. The initial visit included spirometry according to American Thoracic Society standards (10), as well as making a detailed patient profile using a standardized questionnaire and software developed for this purpose (Glaxo Wellcome Community Asthma Management System, GlaxoSmithKline, Canada $[12,13])$. Educators attended a centralized two-day training session for instruction in the use of the questionnaire and the software. The questionnaire formed the basis of the needs assessment and contained items relating to patient history, contacts with the health care system, symptoms, triggers, medications, environment, action plans and action taken during an asthma episode (14). A follow-up visit was scheduled six months (range five to seven months) after the baseline visit, at which time the patients responded to a second standardized questionnaire that assessed current control and contacts with the health care system in the previous six months.

HRQOL was measured at baseline and at six-month follow-up using the self-administered Medical Outcomes Study 36-Item Short Form 1.0 (SF-36) (15), which has been demonstrated to be reliable and valid for asthma $(16,17)$. The SF-36 provides scores ranging from 0 (poor) to 100 (excellent) on eight domains; higher scores represent better function and lower pain levels.

\section{Education program}

The program was based on a model of education implemented in a large community hospital that had previously demonstrated statistically significant improvements in health outcomes (18). Trained asthma educators with a background in nursing or respiratory therapy provided the education. The education program included three levels of education available to the patient relative to their asthma severity and the initial needs assessment. The education was based on the social cognitive theory of learning and behaviour change, and topics included trigger avoidance, environmental control, the role of medications, delivery systems, action plans and self-monitoring skills. Assessment and education took approximately $2 \mathrm{~h}$. A follow-up visit was scheduled for two weeks later to assess control and understanding, and the material was reviewed if necessary. A final follow-up visit was scheduled for six months (range five to seven months) after the baseline visit, at which time the patients responded to a second standardized questionnaire that referenced the previous six months and assessed contact with the health care system, symptoms, triggers, medication, action plan use and action taken during an episode (11). The program was standardized across the centres by means of a training workshop and the use of questionnaires.

\section{Data analysis}

Sites submitted the data directly to Queen's University, where they were analyzed independent of industry. Unpaired $t$ tests (continuous data) and Pearson's $\chi^{2}$ tests (categorical data) were used to compare the characteristics of those who had follow-up data with those who did not. Paired $t$ tests and Wilcoxon signed rank tests were used to assess changes from the initial to the follow-up visit. Between-site differences in changes in outcomes were determined by one-way ANOVA. Stepwise linear regression was used to identify factors associated with change in outcomes, using the difference between baseline and six months as the outcome. Variables were offered into the models on the basis of bivariate association of $\mathrm{P}<0.20$ for each outcome of interest.

Two of the six-month utilization outcomes (physician and emergency room visits) were skewed to the right. To normalize the distribution, the value representing the top $5 \%$ of responses was used as the cut point, and all higher values were collapsed into a single category. For example, the number of regularly scheduled doctor's office visits ranged from 0 to 26 for a six-month period, but $95 \%$ of the patients had values of 12 and under, so the remaining patients were assigned a value of 13 . This method was preferable to the use of nonparametric tests because the authors wanted to develop regression models of the outcomes. A significance level of $\mathrm{P}<0.05$ was used for all outcomes. 


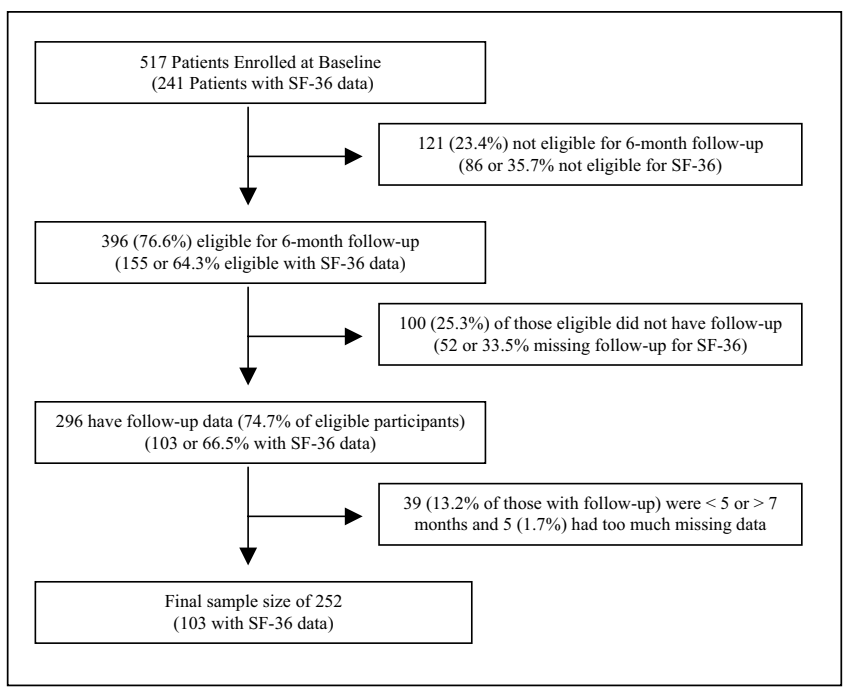

Figure 1) Diagram outlining the determination of the final sample size. SF-36 Medical Outcomes Study 36-Item Short Form 1.0

\section{RESULTS}

\section{Patient characteristics}

Baseline data were collected for 517 patients. Of these, 121 patients were not eligible for their six-month follow-up visit (ie, they had been enrolled in the previous five months) when the study was closed and the analysis was completed. Although the sites did continue to collect data for their own outcomes monitoring, study timelines and funding did not permit waiting an additional five months to accrue follow-up data for those enrolled within five months of the study closing date. Details concerning how the final sample size of 252 patients (63.6\% of eligible patients) was determined are outlined in Figure 1. Of those lost to follow-up, the most common reasons were "moved away" and "unable to reach after repeated attempts." Site-specific sample sizes ranged from 33 to 217 patients at baseline and 16 to 118 patients at follow-up.

Baseline characteristics of those with ("full participants") and without ("lost to follow-up") six-month follow-up data are presented in Table 1. The patients were predominantly middle-aged and female, with a long-standing history of asthma. There were no significant differences between the groups in basic demographics such as age, income, sex or the use of an action plan. There were also no differences in comorbidities, symptoms and family history variables at baseline (data not shown). Full participants were on average, six years older at diagnosis, and a higher proportion were taking inhaled corticosteroids and short-acting beta-agonists compared with those lost to follow-up.

Baseline SF-36 data were collected for 241 patients at six sites (resource limitations prevented one site from collecting HRQOL data), of whom 155 were eligible for the six-month follow-up at study close. Complete follow-up data were available for 103 patients $(66.5 \%)$. A comparison of the baseline scores for those with and without SF-36 scores at follow-up revealed that, with the exception of the role physical domain ( $\mathrm{P}=0.04$; patients with follow-up attained lower scores), there were no significant between-group differences (see Table 1).
TABLE 1

Sample characteristics for full participants and for participants lost to follow-up

\begin{tabular}{|c|c|c|}
\hline Variable & $\begin{array}{c}\text { Full } \\
\text { participants } \\
(n=252)\end{array}$ & $\begin{array}{l}\text { Participants } \\
\text { lost to follow-up } \\
(n=139)\end{array}$ \\
\hline Age (years) (mean $\pm \mathrm{SD})$ & $42.0 \pm 16.1$ & $40.1 \pm 17.6$ \\
\hline Age at diagnosis (years) (mean $\pm \mathrm{SD}$ ) & $26.7 \pm 20.0$ & $20.1 \pm 20.0^{*}$ \\
\hline Female (n [\%]) & $191(75.8)$ & $99(71.2)$ \\
\hline Income less than CDN\$20,000 (n [\%]) & $55(21.8)$ & $31(22.3)$ \\
\hline Income greater than $\mathrm{CDN} \$ 60,000(\mathrm{n}[\%])$ & $15(6.0)$ & $11(7.9)$ \\
\hline Had action plan at initial visit (n [\%]) & $80(31.1)$ & $43(30.9)$ \\
\hline Prescribed inhaled corticosteroid (n [\%]) & $228(90.5)$ & $109(78.4)^{*}$ \\
\hline Prescribed corticosteroid tablets (n [\%]) & $45(17.9)$ & $16(11.5)$ \\
\hline Prescribed short-acting beta-agonist $(\mathrm{n}[\%])$ & ]) $229(90.9)$ & $108(77.7)^{*}$ \\
\hline Prescribed long-acting beta-agonist ( $[\%]$ ) & $29(11.5)$ & $15(10.8)$ \\
\hline SF-36 baseline scores (mean \pm SD) & $\begin{array}{c}\text { Full } \\
\text { oarticipants } \\
(n=103)\end{array}$ & $\begin{array}{c}\text { Participants } \\
\text { lost to follow-up } \\
(n=55) \\
\end{array}$ \\
\hline Physical functioning & $66.4 \pm 26.1$ & $69.2 \pm 24.4$ \\
\hline Role physical & $47.8 \pm 43.3$ & $61.7 \pm 43.5^{\star}$ \\
\hline Role emotional & $62.2 \pm 43.6$ & $71.1 \pm 40.8$ \\
\hline Energy/vitality & $48.0 \pm 21.1$ & $53.9 \pm 18.4$ \\
\hline Mental health & $68.3 \pm 19.8$ & $71.8 \pm 19.6$ \\
\hline Social functioning & $60.4 \pm 15.1$ & $63.4 \pm 13.4$ \\
\hline Bodily pain & $67.6 \pm 26.3$ & $66.4 \pm 27.5$ \\
\hline General health perceptions & $52.9 \pm 20.0$ & $49.3 \pm 23.3$ \\
\hline
\end{tabular}

${ }^{*} P<0.05$ lost to follow-up versus full participants. SF-36 Medical Outcomes Study 36-Item Short Form 1.0

At baseline, there were no significant differences between full participants and those lost to follow-up in most outcomes, including hospital admissions $(\mathrm{P}=0.25)$, emergency department visits $(\mathrm{P}=0.29)$, missed work or school days $(\mathrm{P}=0.13)$, missed leisure time $(\mathrm{P}=0.14)$, and regular physician and specialist visits $(\mathrm{P}=0.20$ and $\mathrm{P}=0.94$, respectively). However, unscheduled visits to both the physician $(\mathrm{P}=0.01)$ and the specialist $(\mathrm{P}=0.01)$ were more prevalent at baseline in those with follow-up data. It should be noted that the 'physician' includes both general practitioners and family physicians.

Health care utilization and absenteeism outcomes

Table 2 outlines changes in health care utilization and absenteeism during the six months before and the six months after the initial visit for the 252 full participants. Some variables were not normally distributed. The median value for regularly scheduled and unscheduled physician visits was one at baseline and zero for all other outcomes measured. At six months, the median value for regularly scheduled physician visits was one and zero for all other outcomes. The Wilcoxon signed rank tests and the paired sample $t$ tests produced similar results, but due to the non-normal distribution, the $\mathrm{P}$ values associated with the Wilcoxon tests are presented in Table 2.

There were statistically significant improvements in all health care utilization and absenteeism outcomes, except regular specialist visits. Although the change in length of hospital stay was statistically significant, the sample size for this analysis was 
TABLE 2

Health care utilization, absenteeism and missed leisure time in full participants $(n=252)$

\begin{tabular}{lccc}
\hline Outcome & $\begin{array}{c}\text { Initial } \\
\text { assessment }\end{array}$ & $\begin{array}{c}\text { Six-month } \\
\text { follow-up }\end{array}$ & P \\
\hline Mean number of physician and specialist visit in previous six & months \\
Regularly scheduled physician visits & 3.13 & 1.96 & $<0.001$ \\
Unscheduled physician visits & 2.71 & 0.51 & $<0.001$ \\
Regularly scheduled specialist visits & 0.86 & 0.96 & 0.214 \\
Unscheduled specialist visits & 0.14 & 0.06 & $<0.05$ \\
Hospital and emergency service utilization in previous six months \\
Mean number of hospital admissions & 0.46 & 0.13 & $<0.001$ \\
Mean number of days in hospital (n=63) & 1.72 & 0.92 & $<0.001$ \\
Mean number of emergency room visits & 0.96 & 0.27 & $<0.001$ \\
Mean number of missed days of work or school and leisure time in \\
previous six months & \multicolumn{3}{c}{0.001} \\
Missed work or school days & 5.04 & 3.85 & $<0.001$ \\
Missed leisure time days & 2.14 & 1.61 & $<0.001$ \\
\hline
\end{tabular}

Mean values are based on total number of visits or admissions divided by the sample size. For example, there was an average of 0.46 hospital admissions per person, but, in fact, only 63 patients were actually hospitalized

quite small. Only 63 patients had had a hospitalization in the six months preceding their education visit, and of those, only 20 patients indicated that they had a hospitalization in the six months after their initial assessment. Two patients had a hospitalization in the six months after their education visit but had had none before that visit.

\section{HRQOL outcomes}

SF-36 domain scores at the initial and the follow-up visits are illustrated in Figure 2. SF-36 scores were consistently lower than the Canadian normative population (19) on all domains of the SF-36 at the initial visit. Six months after asthma education, there were statistically significant improvements in all HRQOL domains except mental health, which improved only slightly. In addition, the change in five domains (physical function, role physical, role emotional, bodily pain and vitality) exceeded five points, which is considered by the developers to be a clinically and socially meaningful change (15). The change in two domains fell just short of five points, including social function (4.5) and general health perceptions (4.6).

\section{Medication use}

There were few significant changes in medication use reported by patients from baseline to the six-month follow-up. In particular, there were no significant differences in the proportion taking an inhaled corticosteroid (90.5\% versus $88.3 \%$ ) or short-acting beta-agonist ( $90.9 \%$ versus $87.2 \%)$. Use of longacting beta-agonists increased from $11.5 \%$ to $20.6 \%(\mathrm{P}=0.02)$, while current use of oral corticosteroids, either chronic use or for acute exacerbations, decreased from $17.9 \%$ to $6.2 \%$ $(\mathrm{P}=0.02)$.

\section{Practice setting}

Site-specific data cannot be reported due to confidentiality agreements. However, the aggregate data reported are representative of the findings at each of the seven sites, regardless of setting.

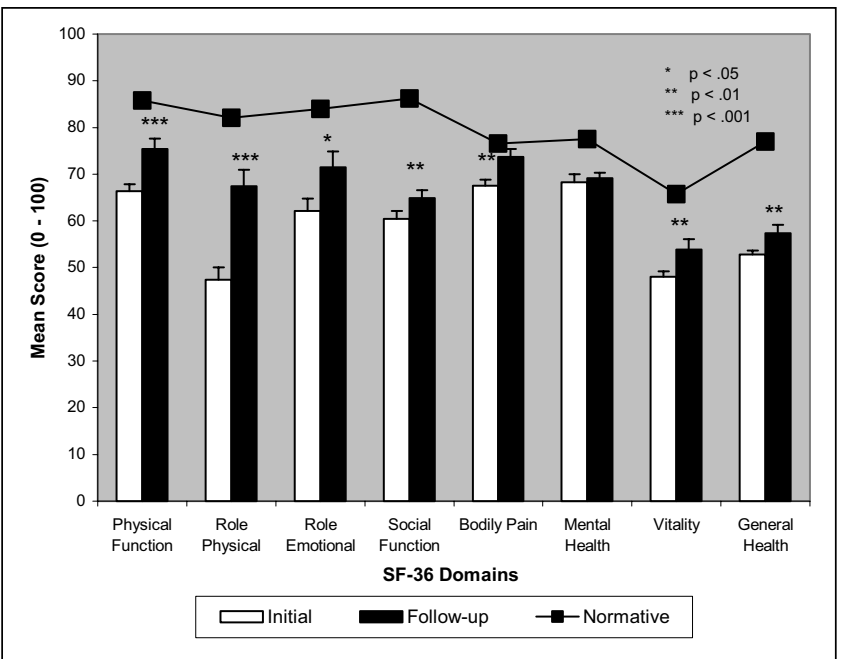

Figure 2) Changes in Medical Outcomes Study 36-Item Short Form 1.0 (SF-36) domain scores from initial visit to six-month follow-up visit

One-way ANOVA indicated that there were no betweensite differences in the changes in regular or unscheduled doctor's office visits, unscheduled specialist visits or hospital admissions. Small differences were found in regular specialist visits $(\mathrm{F}=2.65, \mathrm{P}<0.05)$, emergency department visits $(\mathrm{F}=2.40$, $\mathrm{P}<0.05)$, absenteeism $(\mathrm{F}=2.75, \mathrm{P}<0.05)$ and missed leisure time $(\mathrm{F}=3.19, \mathrm{P}<0.01)$.

All sites that collected SF-36 data showed consistent improvement in domain scores. However, significance levels of the findings varied with the sample size at each site. The site with the largest sample had significant changes in all but one domain (mental health). Two sites had sample sizes too small for a valid comparison, although they were included in the aggregate analysis. For both of these sites, however, all domain scores improved. The remaining sites ranged from two to five statistically significant changes, but all showed either improvement or little improvement. Mental health, social functioning and role emotional function tended to have the smallest changes at these remaining sites, which was consistent with the aggregate analysis. There were also no significant betweensite differences in changes in SF-36 scores.

The few observed associations between outcomes and the setting or site were weak. Individual pair-wise comparisons revealed that the community hospital site and one CACC site had greater improvement in the number of regular specialist visits than two other CACC sites $(\mathrm{P}<0.05$ in all four cases). The community hospital, the academic health sciences centre and two different CACC sites had greater improvement than two other CACC sites in emergency room visits $(\mathrm{P}<0.05$ in all cases). Finally, the community hospital and two CACC sites had greater improvement in absenteeism and missed leisure time than one other CACC site $(\mathrm{P}<0.05$ in all cases). There was no evidence that one setting was superior to the others.

Predictors of outcome

A large number of baseline variables were associated with changes in the outcomes. The models for all health care 
utilization and absenteeism outcomes were highly significant $(\mathrm{P}<0.001)$, with $\mathrm{F}$ ratios ranging from 5.51 to 14.17 . The models identified a variety of covariates, including patient characteristics, comorbid conditions, triggers, environmental factors and medications. Due to the complexity of the data collected and the large number of covariates identified, the factors that were significantly associated with greater or lesser improvement are simply identified as such, and the models are summarized in the appendixes.

The models for the eight domains of the SF-36 were significant, accounting for between 13\% (general health perceptions) and $44 \%$ (physical functioning) of the variation in the improvement in HRQOL. Several factors were often associated with changes in more than one domain. Gastroesophageal reflux, venetian blinds and open shelving at baseline were associated with greater improvement in three domains, while family history of eczema, wool bedding and confidence in managing asthma were associated with less improvement in three domains. These models are also presented in the appendixes.

\section{DISCUSSION}

The present study has shown that a standardized asthma selfmanagement program administered in diverse practice settings can result in statistically significant and clinically relevant improvements in asthma morbidity. Asthma education was associated with improvements in outcomes regardless of geographic site or physical setting (CACC, community hospital or academic health sciences centre). There were no between-site differences in 13 of the 17 outcomes, and for the remaining four outcomes, there was no consistent pattern of one site out-performing others. The few differences in magnitude of change in outcomes between sites are most likely attributable to site differences in sample size and/or disease severity.

The standardized asthma education program administered in the present study was associated with improvements in scheduled and unscheduled physician visits, unscheduled specialist visits, emergency room visits, hospital admissions, hospitalized days, missed work or school days and missed days of leisure time, comparable in magnitude with meta-analyses of controlled clinical trials (9). However, hospitalizations were infrequent, and it is possible that the magnitude of reduction in hospitalizations may therefore have been overestimated by the short study period. The small (but nonsignificant) increase in regularly scheduled specialist visits may, in fact, represent better adherence with guideline recommendations $(3,6)$ for regular follow-up care. Our findings are consistent with the beneficial effects demonstrated recently in a national pharmacy-based asthma education intervention (20) and provide data to substantiate claims for increased availability of asthma education programs in Canada $(21,22)$.

There were also statistically significant improvements in seven of the eight domains of the SF-36. It is interesting to note, however, that with the exception of bodily pain, there were still fairly large residual differences between the asthma patients and the age- and sex-adjusted normative SF-36 data, even six months after asthma education, indicating a significant burden of illness in this population.
Regression analysis of baseline characteristics allowed us to explore potential patient or setting characteristics that were more or less likely to benefit from the educational intervention used. A number of patient characteristics, such as sociodemographic characteristics, comorbid conditions, family history of certain conditions, symptoms, triggers, medication use and environmental aspects, were identified as predictive of the degree of improvement in outcomes after asthma education. There was a significant improvement in all but one outcome, therefore, it is important to note that the characteristics are associated with greater and less improvement, rather than with improvement and deterioration. Once aware of these characteristics, education programs may target and be tailored to certain groups to optimize outcomes, such as those with comorbidities (sinusitis and gastroesophageal reflux), a family history of asthma, seasonal variation in symptoms, exerciseinduced symptoms or limitations and significant environmental triggers, as well as patients who have recently changed medications and patients who report high anxiety levels or low confidence in managing asthma.

While most of the relationships identified in the regression analysis are intuitive, some are not, due to the fact that the variables in the regression models were collected at baseline. For example, the presence of a fireplace, gas stove or furry pet was sometimes associated with greater improvement. Comparing frequency distributions for triggers at the time of the initial assessment with the follow-up assessment indicated that this improvement is related to implementation of environmental control or avoidance measures after asthma education. Other variables, such as the use of a verbal or written action plan, were sometimes associated with less improvement. This probably reflects the likelihood that those already using action plans at the initial visit had better baseline asthma control, so that less improvement was possible. Medications, such as use of inhaled long-acting beta 2 -agonists and corticosteroids (inhaled or oral) at the time of the initial visit, were also associated with greater improvement. While the education process may have improved adherence, the possibility that patients were put on more aggressive treatment just before their initial visit cannot be ruled out with these data, because data on the duration of medication use were not collected.

Approximately 35\% of eligible patients were lost to followup for health care utilization, absenteeism and HRQOL outcomes, raising the possibility that the study group represents a survivor population. However, there were few differences between the group lost to follow-up and full participants at the time of the baseline evaluation. The greater proportion of participants prescribed inhaled corticosteroids at baseline, if anything, may have minimized the potential for improvement. Without knowledge of actual use, it is difficult to make inferences as to the impact of the greater proportion of participants prescribed short-acting beta-agonists. Shorter duration of asthma, older age and lower role physical scores may be characteristics of patients more likely to complete an asthma education program.

It should be noted that a control group is required when one wishes to determine, with certainty, the magnitude of change attributable to an intervention and to infer causality. Because asthma patients enrolled in any study tend to improve, for the 
present study, we may not attribute the magnitude of improvement solely to the standardized asthma education program. Some of the improvements in the outcomes noted could have been related to other factors or cointerventions, such as changes in physician or pharmacist behaviours, changes in medication during the study period (eg, increased use of long-acting beta-agonists) or exogenous factors such as seasonality, or they could have been part of a pre-existing and ongoing trend. Adherence was not measured, but would be expected to improve as a direct, desired consequence of education and, as such, is not a true 'confounder'. The changes in medications observed (increased proportion using long-acting beta-agonists and reduced proportion using oral corticosteroids) are likely reflective of improved adherence with recommended medication management - also to be expected as a result of asthma education. The data were collected over several years with patients enrolled during all seasons, making seasonality unlikely. Nonetheless, the observational pre-post design of this study has been adequate to answer the research questions: comparing the degree of change for outcomes of asthma education between multiple sites and determining baseline characteristics associated with improvements (23).

\section{CONCLUSIONS}

The findings of the present study at multiple sites are consistent with those of other studies that have demonstrated significant improvements in health care utilization at single sites $(9,11,21,24)$. Our results also underscore the usefulness and the importance of including formal assessments of HRQOL when studying asthma outcomes, as promoted by others $(16,17,25)$, and support findings in favour of the use of the SF-36 as a generic measure of HRQOL in this population $(15,26,27)$.

The significant decline in health care utilization implies that substantial health care savings may be possible through the widespread implementation of standardized asthma education programs. Health care savings were not directly assessed within the present study because they are likely to vary by province. However, participation in an asthma education program generally takes only a few hours, which is likely substantially less costly to the health care system than physician and specialist visits, emergency department visits and hospitalizations.

The aim of the present study was not to confirm the efficacy of education, because that has already been demonstrated by randomized, clinical trials. Rather, this study sought to determine the effectiveness of a standardized asthma education program, administered in a variety of settings, in improving a number of outcomes, as well as the factors associated with a change in outcome. The present pragmatic study has shown that a standardized asthma education program may be effective when administered in a variety of diverse practice settings and may be associated with significant and comparable improvements in patient outcomes.

Dissemination and implementation of asthma management guidelines could be greatly enhanced by the widespread implementation of standardized asthma education programs. Additional comparative and controlled studies are required to determine the optimal program to achieve these ends in Canada.

\begin{tabular}{|c|c|c|c|}
\hline \multicolumn{4}{|c|}{$\begin{array}{l}\text { APPENDIX } 1 \\
\text { Baseline characteristics associated with changes in } \\
\text { physician and specialist utilization }\end{array}$} \\
\hline \multicolumn{4}{|c|}{ Baseline characteristics associated with greater improvement ${ }^{*}$} \\
\hline \multicolumn{4}{|c|}{ Arthritis; reflux; hives; infrequent peak flow measurement } \\
\hline \multicolumn{4}{|c|}{ Personal or family history of eczema or medication reactions } \\
\hline \multicolumn{4}{|c|}{ More frequent attacks; exposure to environmental smoke } \\
\hline \multicolumn{4}{|l|}{ Asthma worsened by self-care activities } \\
\hline \multicolumn{4}{|l|}{ Gas stove, old mattress, fireplace in home } \\
\hline \multicolumn{4}{|c|}{ Prescribed inhaled long-acting beta $_{2}$-agonists or corticosteroid tablets } \\
\hline \multicolumn{4}{|l|}{ Change in medications or workplace } \\
\hline \multicolumn{4}{|l|}{ Community site } \\
\hline \multicolumn{4}{|c|}{ Baseline characteristics associated with less improvement ${ }^{*}$} \\
\hline \multicolumn{4}{|c|}{ Family history of asthma; presence of furry pets } \\
\hline \multicolumn{4}{|c|}{ Confident managing asthma and use of action plan (already well controlled) } \\
\hline \multicolumn{4}{|c|}{$F$ ratios, $P$ values and $R^{2}$ values for the models } \\
\hline Change in regular physician visits & $\mathrm{F}=7.34$ & $\mathrm{P}<0.001$ & $R^{2}=0.26$ \\
\hline Change in unscheduled physician visits & $F=14.17$ & $P<0.001$ & $R^{2}=0.47$ \\
\hline Change in regular specialist visits & $F=6.63$ & $P<0.001$ & $R^{2}=0.26$ \\
\hline Change in unscheduled specialist visits & $\mathrm{F}=5.51$ & $P<0.001$ & $\mathrm{R}^{2}=0.25$ \\
\hline
\end{tabular}

${ }^{*}$ All factors listed are significant at $P<0.05$

\section{APPENDIX 2 \\ Baseline characteristics associated with changes in emergency room and hospital use}

Baseline characteristics associated with greater improvement ${ }^{*}$

Female; diabetics

Lower income; difficulty paying for medications

Current smokers; past smokers; exposure to smoke

Family history of medication reactions

Gas stove; polyester pillow; furry pet

Asthma triggered by smoke, cold air, certain foods

Basement environment; use of more inhalers per month

Prescribed inhaled long-acting beta ${ }_{2}$-agonists or corticosteroid tablets

Baseline characteristics associated with less improvement*

Reflux; sinusitis

Asthma worsened by exercise

Use of action plan at baseline (already well controlled)

$F$ ratios, $P$ values and $R^{2}$ values for the models

\begin{tabular}{llll}
\hline Change in emergency room visits & $\mathrm{F}=6.94$ & $\mathrm{P}<0.001$ & $\mathrm{R}^{2}=0.33$ \\
Change in hospital admissions & $\mathrm{F}=7.51$ & $\mathrm{P}<0.001$ & $\mathrm{R}^{2}=0.35$ \\
Change in number of hospitalized days & $\mathrm{F}=13.08$ & $\mathrm{P}<0.001$ & $\mathrm{R}^{2}=0.39$ \\
\hline
\end{tabular}

${ }^{*}$ All factors listed are significant at $P<0.05$

\section{APPENDIX 3}

Baseline characteristics associated with changes in absenteeism and missed leisure time

Baseline characteristics associated with greater improvement*

Older age

Anaphylaxis in past 12 months; cough with phlegm

Asthma triggered by air pollution, stairs

Baseline characteristics associated with less improvement*

Frequent wheezing; high anxiety

Asthma triggered by smoke, open shelving, dust

Asthma worse in spring; had a skin prick test

$F$ ratios, $P$ values and $R^{2}$ values for the models

\begin{tabular}{llll}
\hline Change in missed work or school & $\mathrm{F}=6.97$ & $\mathrm{P}<0.001$ & $\mathrm{R}^{2}=0.25$ \\
Change in missed leisure time & $\mathrm{F}=6.20$ & $\mathrm{P}<0.001$ & $\mathrm{R}^{2}=0.26$ \\
\hline
\end{tabular}

${ }^{*}$ All factors listed are significant at $P<0.05$ 


\section{APPENDIX 4 \\ Baseline characteristics associated with changes in Medical Outcomes Study 36-Item Short Form 1.0 (SF-36) domain scores}

Baseline characteristics associated with greater improvement ${ }^{\star}$

Reflux; chest tightness; wheezing; history of smoking

Female

Food, odours, moderate activity, climbing stairs and cold air are triggers

Open shelving, venetian blinds, old mattress or dehumidifier in home

Asthma has interfered with social life

More frequent attacks

Difficulty at work or changed work recently

Tremors and headaches as side effects of medication

Always carries blue puffer; has action plan

At one of the CCAC community sites

Baseline characteristics associated with less improvement*

Hives; diabetes; arthritis

Cough with or without phlegm

Sinusitis; family history of eczema

Wool bedding, old mattress in home

Bending, kneeling and smoke exposure are triggers

Asthma worse in autumn

Prescribed inhaled corticosteroids; use of more inhalers per month

More confident patients (already well managed)

More anxious patients

Frequent night awakenings

$F$ ratios, $P$ values and $R^{2}$ values for the models

\begin{tabular}{llll}
\hline Change in physical function & $\mathrm{F}=8.84$ & $\mathrm{P}<0.001$ & $\mathrm{R}^{2}=0.49$ \\
Change in role physical & $\mathrm{F}=6.91$ & $\mathrm{P}<0.001$ & $\mathrm{R}^{2}=0.45$ \\
Change in role emotional & $\mathrm{F}=5.58$ & $\mathrm{P}<0.001$ & $\mathrm{R}^{2}=0.37$ \\
Change in social function & $\mathrm{F}=4.14$ & $\mathrm{P}<0.01$ & $\mathrm{R}^{2}=0.18$ \\
Change in bodily pain & $\mathrm{F}=5.77$ & $\mathrm{P}<0.001$ & $\mathrm{R}^{2}=0.29$ \\
Change in mental health & $\mathrm{F}=4.65$ & $\mathrm{P}<0.001$ & $\mathrm{R}^{2}=0.27$ \\
Change in vitality & $\mathrm{F}=6.70$ & $\mathrm{P}<0.001$ & $\mathrm{R}^{2}=0.49$ \\
Change in general health perceptions & $\mathrm{F}=4.30$ & $\mathrm{P}<0.01$ & $\mathrm{R}^{2}=0.16$ \\
\hline
\end{tabular}

${ }^{*}$ All factors listed are significant at $P<0.05$

\section{REFERENCES}

1. Boulet LP, Chapman KR, Green LW, FitzGerald JM. Asthma education. Chest 1994;106(Suppl 4):184S-96S.

2. Global Initiative for Health (GINA). Global Strategy for Asthma Management and Prevention NHLBI/WHO Workshop Report. Publication Number 95-3659. Bethesda: National Institutes of Health, National Heart, Lung and Blood Institute, 1995.

3. Boulet LP, Becker A, Berube D, Beveridge R, Ernst P. Canadian Asthma Consensus Report, 1999. Canadian Asthma Consensus Group. CMAJ 1999;161(Suppl 11):S1-S6.

4. Asthma in Canada: A Landmark Survey. Mississauga: Glaxo Wellcome Inc, 2000.

5. Ontario Ministry of Health and Long-Term Care. Taking Action on Asthma: Report of the Chief Medical Officer of Health. Toronto: Queen's Printer for Ontario, 2000.
6. National Asthma Education and Prevention Program Expert Panel. Guidelines for the Diagnosis and Management of Asthma. NIH Publication 97-4051. Bethesda: US Department of Health and Human Services, Public Health Services, National Institute of Health, National Heart, Lung and Blood Institute, 1997.

7. Jin R, Choi B, Chan B, et al. Physician asthma management practices in Canada. Can Respir J 2000;7:456-65.

8. Boulet LP, Becker A, Berube D, Ernst P, Beveridge R. 1998 revision of the Canadian Asthma Consensus Guidelines. Asthma Consensus Conference Editorial Committee. Can Respir J 1999;6:231-2.

9. Gibson PG, Coughlan J, Wilson AJ, et al. Self-management education and regular practitioner review for adults with asthma. Cochrane Database Syst Rev 2000;2:CD001117.

10. Standards for the diagnosis and care of patients with chronic obstructive pulmonary disease (COPD) and asthma. Am Rev Respir Dis 1987;136:225-44.

11. Hopman WM, Owen JG, Gagne E. Assessment of the effect of asthma education on outcomes. Manag Care Interface 1999;12:89-93.

12. Community Asthma Care Centre Executive Summary. Mississauga: Glaxo Wellcome Canada Inc, 1996.

13. Community Asthma Care Centres. First National Program Evaluation: The Impact of Patient Assessment and Education on Asthma Health Status. Mississauga: Glaxo Wellcome Canada Inc, 2000.

14. Lougheed MD. Asthma outcomes evaluation: Analysis of an asthma education database. Publication Number AAT MQ42655, MAI 38/02. Diss Abstr Int 2000;61:427.

15. Ware JE. SF-36 Health Survey Manual and Interpretation Guide. Boston: The Health Institute, New England Medical Centre, 1993.

16. Juniper EF. Assessing health-related quality of life in asthma. Can Respir J 1997;4:145-51.

17. Bousquet J, Knani J, Dhivert H, et al. Quality of life in asthma. I. Internal consistency and validity of the SF-36 questionnaire. Am J Respir Crit Care Med 1994;149:371-5.

18. Tilly KF, Garvey NJ, Gold M, Powell E, Proudlock ML. Outcomes management and asthma education in a community hospital: Ongoing monitoring of health status. Qual Manag Health Care 1996;4:67-78.

19. Hopman WM, Towheed T, Anastassiades T, et al. Canadian normative data for the SF-36 health survey. CMAJ 2000;163:265-71.

20. Diamond SA, Chapman KR. The impact of a nationally coordinated pharmacy-based asthma education intervention. Can Respir J 2001;8:261-5.

21. Boulet LP. Asthma education: What has been its impact? Can Respir J 1998;5(Suppl A):91A-6A.

22. Cowie RL, Cicutto L, Boulet LP; Patient Education Program Committee, Canadian Network for Asthma Care. Asthma education and management programs in Canada. Can Respir J 2001;8:416-20.

23. Grimes DA, Schulz KF. Bias and causal associations in observational research. Lancet 2002;359:248-52.

24. Gibson PG, Coughlan J, Wilson AJ, et al. Limited (information only) patient education programs for adults with asthma. Cochrane Database Syst Rev 2000;2:CD001005.

25. Erickson SR, Christian RD Jr, Kirking DM, Halman LJ. Relationship between patient and disease characteristics, and health-related quality of life in adults with asthma. Respir Med 2002;96:450-60.

26. Ried LD, Nau DP, Grainger-Rousseau TJ. Evaluation of patient's Health-Related Quality of Life using a modified and shortened version of the Living With Asthma Questionnaire (ms-LWAQ) and the medical outcomes study, Short-Form 36 (SF-36). Qual Life Res 1999;8:491-9.

27. Ware JE, Kemp JP, Buchner DA, Singer AE, Nolop KB, Gross TF. The responsiveness of disease-specific and generic health measures to changes in the severity of asthma among adults. Qual Life Res $1998 ; 7: 235-44$ 


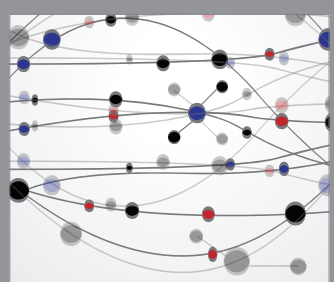

The Scientific World Journal
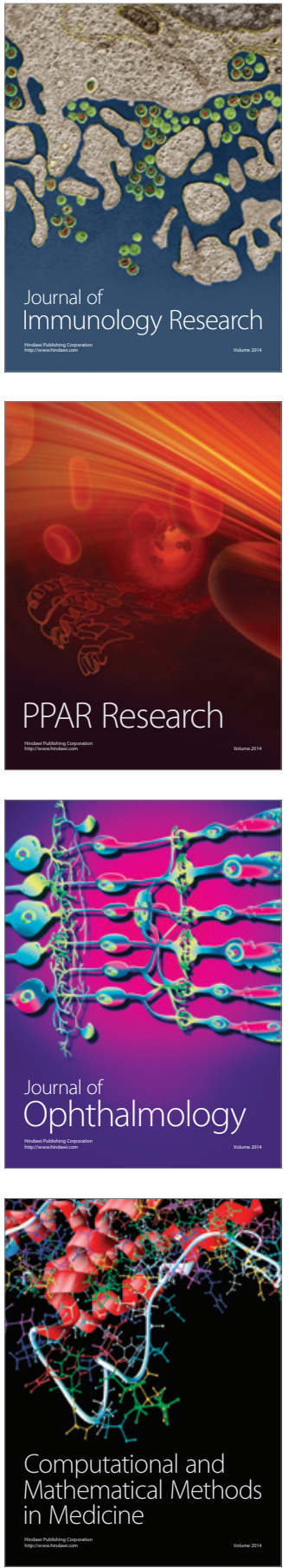



Gastroenterology Research and Practice



\section{Hindawi}

Submit your manuscripts at

http://www.hindawi.com
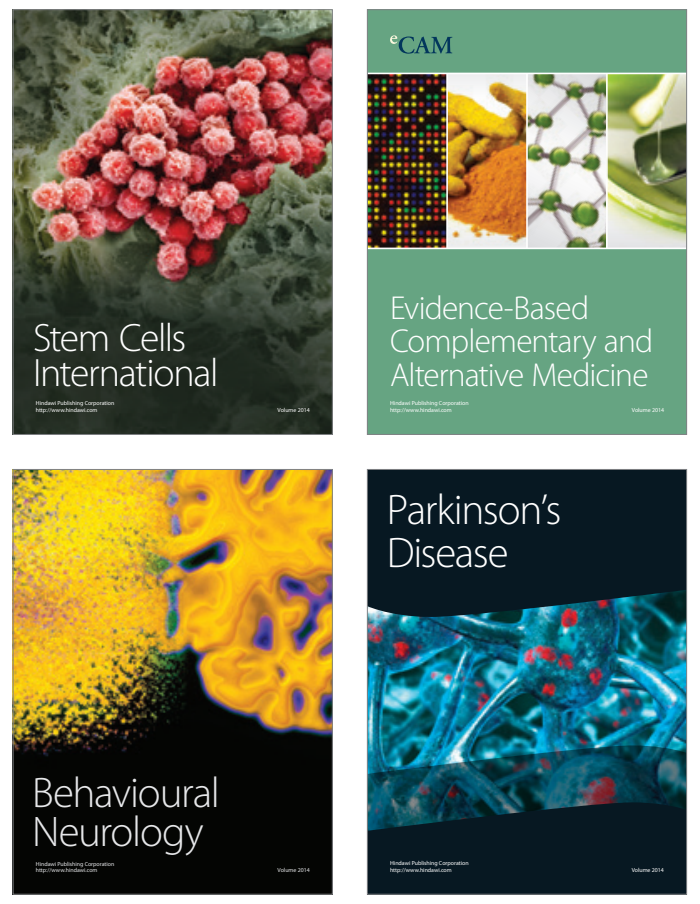


Disease Markers
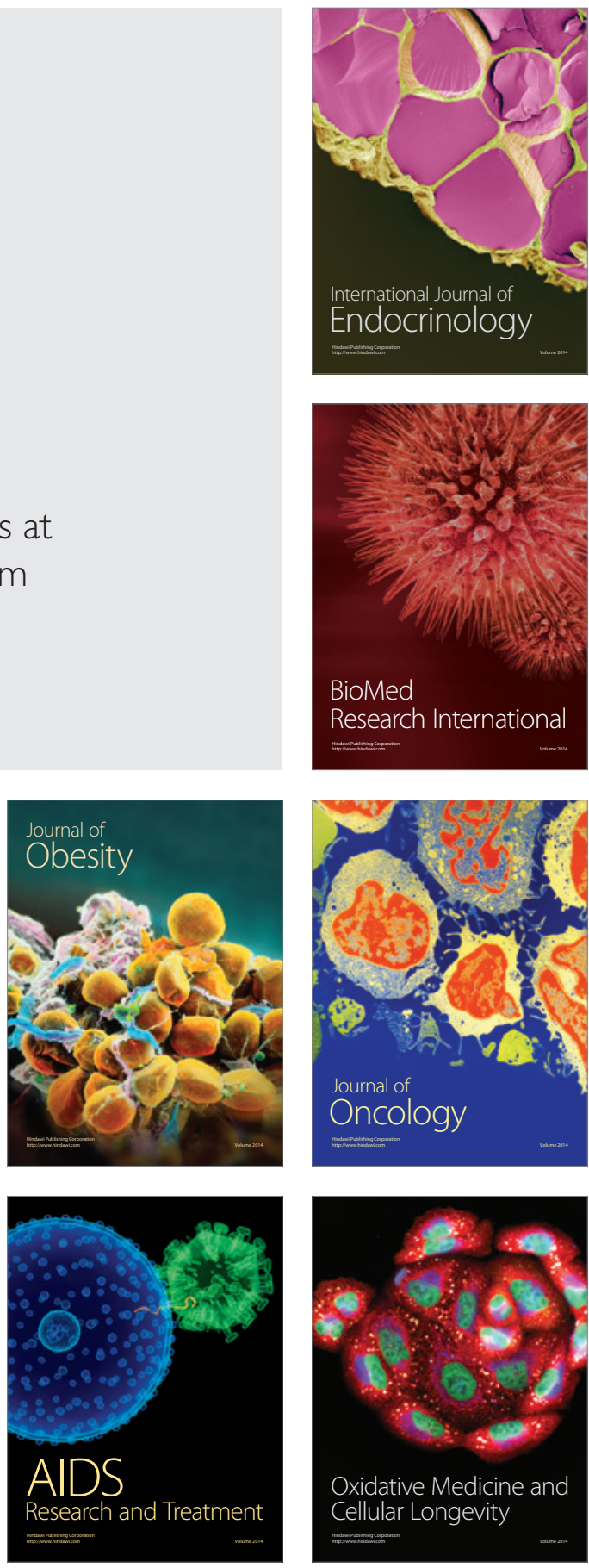